\title{
Study on the Antimicrobial activity and Minimum I nhibitory Concentration of Essential Oils of Spices
}

\author{
A.J agadeesh Babu* ${ }^{1}$, A.Rupa Sundari ${ }^{1}$, J Indumathi ${ }^{1}$, R.V.N.Srujan ${ }^{2}$ and M.Sravanthi ${ }^{2}$ \\ 1.Department of Veterinary Public Health \\ 2. Department of Pharmacology and Biochemistry \\ College of Veterinary Science, Tirupati (A.P.) - 517 502, India. \\ * Corresponding author E-mail: drjagadeeshvet@yahoo.co.uk \\ Published Online : 30-04-2011
}

\begin{abstract}
Antibacterial activity and minimum inhibitory concentration (MIC) of essential oils of garlic, clove and cinnamon were estimated by using various bacterial pathogens. Among the bacterial pathogens tested against essential oil of garlic, Staphylococcus aureus was found to be highly sensitive followed by E.coli. L.monocytogenes and S.pyogenes were found to be less sensitive. The essential oil of clove was found to be most active against $S$.aureus followed by $E$. coli. B.cereus and C. jejuni. The essential oil of cinnamon was also most active against S.aureus followed by E.coli and C.jejuni. Essential oil of cinnamon was found to be active against all the bacterial pathogens tested, when compared to garlic and clove oils. However Staph. aureus, E. coli and C.jejuni were found to be most sensitive to the action of essential oils of garlic, clove and cinnamon. Among the bacterial pathogens tested against essential oils of spices to know the MIC by agar diffusion method, C.jejuni was found to be most sensitive to the essential oil of garlic followed by E.coli, S. typhimurium and Staphylococcus aureus. L. monocytogenes and Methicillin resistant Staph. aureus were found to be comparatively less sensitive. Essential oil of clove was also found to be highly effective against $C$.jejuni followed by E.coli, S.typhimurium and S.aureus. Again L.monocytogenes and Methicillin resistant S.aureus were comparatively less sensitive to the action of essential oil of clove. All most all the bacterial pathogens tested were found to be sensitive to the essential oil of cinnamon. However C.jejuni and E.coli were found to be most sensitive followed by S.typhimurium, Staph. aureus and Methicillin resistant Staph. aureus .
\end{abstract}

Key words: Essential oils of garlic, clove, cinnamon, antimicrobial activity, minimum inhibitory concentration.

\section{I ntroduction}

Due to the awareness among the public now a days, major importance has been given for meat preservation which has been characterized for microbiologically stable meat. Recently there has been an increasing interest in discovering new natural antimicrobial substances or bio preservatives for the preservation of meat and meat products. Bio preservatives include a range of natural products from plants, animals and microorganisms which can be used to improve the keeping quality of foods. Being plant natural food stuffs, spices appear to be an alternative for the chemical antimicrobials to the consumers who tend to question their safety. Spices active compounds have been included in class of naturally occurring food preservatives and their inclusion in foods allowed by food production regulatory offices. Although, spices have been well known for their medicinal, preservative and antioxidant properties, currently they have been used with primary purpose of enhancing the flavour of foods rather than extending shelf-life. In recent years antimicrobial properties of spices have been documented and interest continued to the present. There is little information available emphasizing the preservative and antimicrobial role of spices in the prevention of meats.

\section{Materials and methods}

The essential oils of spices viz., garlic, clove and cinnamon were obtained from M/S Plant lipids Ltd, Cochin, Kerala. The reference strains of Escherichia coli (MTCC 452), Staphylococcus aureus (MTCC 3103) and Salmonella typhimurium (MTCC 1251) were obtained from the Institute of Microbial Technology (IMTECH), Chandigarh.

The reference strains of Bacillus cereus, Campylobacter jejuni and Listeria monocytogenes were procured from the Department of Microbiology, Christian Medical College, Vellore, Tamilnadu. The reference strains of Streptococcus pyogenes and Methicillin resistant Staphylococcus aureus were 
Table-1: Antibacterial activity of essential oils of garlic, clove and cinnamon on various bacterial pathogens

\begin{tabular}{llll}
\hline Bacterial pathogens & \multicolumn{2}{c}{ Inhibition zone ( mm ) formed by essential oil of } \\
\cline { 2 - 4 } & Garlic & Clove & Cinnamon \\
\hline Escherichia coli & $18.00+0.03$ & $21.00+0.06$ & $26.00+0.08$ \\
Staphylococcus aureus & $19.00+0.12$ & $25.00+0.05$ & $31.00+0.16$ \\
Salmonella typhimurium & $13.00+0.08$ & $22.00+0.14$ & $24.00+0.03$ \\
Bacillus cereus & $14.00+0.06$ & $12.00+0.03$ & $18.00+0.05$ \\
Campylobacter jejuni & $13.00+0.13$ & $13.00+0.08$ & $26.00+0.06$ \\
Listeria monocytogenes & $17.00+0.18$ & $21.00+0.08$ & $25.00+0.06$ \\
Streptococcus pyogenes & $12.00+0.05$ & $18.00+0.02$ & $21.00+0.11$ \\
Methicillin resistant Staphylococcus aureus & $13.00+0.02$ & $19.00+0.05$ & $23.00+0.07$ \\
\hline
\end{tabular}

obtained from the Department of Veterinary Public Health, College of Veterinary Science, Rajendranagar, Hyderabad. The cultures were maintained at $4^{0} \mathrm{C}$ in Brain Heart Infusion broth and were tested for purity, morphology and biochemical characters for every 15 days.

Preparation of bacterial culture: The bacterial pathogens viz., Escherichia coli, Staphylococcus aureus and Salmonella typhimurium were inoculated into Brain Heart Infusion broth and incubated at $37^{\circ} \mathrm{C}$ overnight. The inoculum was then centrifuged (Remi Model: Remi R8 ) at $8000 \mathrm{rpm}$ for 10 minutes. The supernatant was discarded and the pellet was mixed in sterile normal saline and centrifuged at $8000 \mathrm{rpm}$ for 10 minutes. Then the cells were washed twice with normal saline and the concentration of the cells was matched to the Nephelometer tube no 4 which gave a cell concentration of $10^{9}$ cells / $\mathrm{ml}$ of culture. This culture was used as inoculum for the seeded plates in determining the antimicrobial activity and minimum inhibitory concentration of essential oils of spices.

Dilution of the essential oils of spices: All the essential oils of spices were diluted in Diethyl ether. Dilutions were made from 1: 50 to 1:1300. All concentrations of the essential oils were prepared a day prior to use and stored at $4^{\circ} \mathrm{C}$.

Test to determine the antimicrobial activity: The disc diffusion method was used to determine the antimicrobial activity of the essential oils of spices. The volume of $0.1 \mathrm{ml}$ ( approximately $10^{9}$ cells $/ \mathrm{ml}$ ) of the tested microorganisms grown in liquid growth media at $37^{\circ} \mathrm{C}$ was inoculated on Muller-Hinton growth media and then spread on the entire surface of the Petri dish using a sterile swab. Then sterile paper discs (Whatman $1.6 \mathrm{~mm}$ ) with $30 \mu \mathrm{l}$ absorbed essential oil of spices were placed on to the Muller-Hinton agar by pressing gently. The plates were incubated at $35 \pm$ $1^{0} \mathrm{C}$ for 48 hours. After the incubation period the inhibition zones around the paper discs were measured in millimeters. The sensitivity of the individual oil was classified by the diameter of the inhibition zone as per the procedure of Ponce et al (2003) and Moreira et al (2005). The experiment was repeated in duplicate for all of the test strains.

Non sensitive (-) : For total diameter smaller than $8 \mathrm{~mm}$ Sensitive $(+) \quad:$ :For total diameter between $9-14 \mathrm{~mm}$ Very sensitive $(++) \quad$ : For total diameter between $15-19 \mathrm{~mm}$ Extremely sensitive(+++) : For total diameter larger than $20 \mathrm{~mm}$

Test to determine the minimum inhibitory concentration: As per the procedure followed by Moreira et al., ( 2005 ) agar diffusion assay was used to determine minimum inhibitory concentration of the essential oils of spices. In to $100 \mathrm{ml}$ of sterile Tryptic soy agar which was maintaining at $45^{\circ} \mathrm{C}, 1 \mathrm{ml}$ of the prepared bacterial culture was added to give a final concentration of $10^{7}$ cells $/ \mathrm{ml}$ in the medium. The culture was thoroughly mixed in the appropriate artificial medium and the plates were poured, allowed to solidify and placed in a refrigerator for 10 minutes. Holes were then punched into the agar to create wells, into which measured volume of $100 \mu \mathrm{l}$ of the essential oil of spices were placed after sealing the bottom of the well with sterile agar of $1 \%$. This ensured that radial diffusion from the well gave a clear and easily measured zone of inhibition. The plates were then incubated at $37^{\circ} \mathrm{C}$ for 24 hours. The inhibition zones were measured after the incubation period. This assay was carried out in duplicate with two replicates on each occasion.

\section{Results and Discussion}

Antibacterial activity of essential oils of garlic, clove and cinnamon: The mean \pm SE values of the antibacterial activity of essential oils of garlic, clove and cinnamon are presented in Table 1.

The results obtained in this study indicated that the bacterial pathogens tested against the essential oil of garlic, Staphylococcus aureus was found to be highly sensitive to its action followed by Escherichia coli, Listeria monocytogenes, Bacillus cereus, 
Study on the Antimicrobial activity and Minimum Inhibitory Concentration of Essential Oils of Spices

Table-2: Minimum inhibitory concentration of various concentrations of essential oil of garlic on the growth of bacterial pathogens

\begin{tabular}{|c|c|c|c|c|c|c|c|}
\hline \multirow[t]{2}{*}{ Bacterial pathogens } & \multicolumn{6}{|c|}{ Various concentrations of essential oil of garlic } & \multirow[b]{2}{*}{$1: 1300$} \\
\hline & $1: 150$ & $1: 250$ & $1: 500$ & $1: 600$ & $1: 700$ & $1: 1000$ & \\
\hline Escherichia coli & ++ & ++ & + & + & + & + & ---- \\
\hline Salmonella typhimurium & ++ & ++ & ++ & + & + & + & ---- \\
\hline Bacillus cereus & ++ & ++ & ++ & + & + & ---- & ---- \\
\hline Campylobacter jejuni & ++ & ++ & ++ & ++ & ++ & ++ & + \\
\hline Methicillin resistant $\mathrm{S}$. aureus & ++ & ++ & + & + & + & ---- & ---- \\
\hline
\end{tabular}

$+: 08-09 \mathrm{~mm},++: 10-13 \mathrm{~mm},+++: 14-16 \mathrm{~mm}$

Campylobacter jejuni, Methicillin resistant Staphylococcus aureus, Salmonella typhimurium and Streptococcus pyogenes. The antibacterial activity of essential oil of garlic may be attributed to allicin the antimicrobial component of garlic. The broad spectrum antimicrobial activity of allicin and its associated molecule ajoene appears to be due to the multiple inhibitory effects on various thiol dependant enzymatic systems such as, alcohol dehydrogenase, thioredoxin reductase and RNA polymerase which can affect essential metabolism of cysteine proteinase activity involved in virulence of the pathogen (Ankri and Mirelman, 1999).

The results obtained from this study were comparable with the results of El-Khatib and Abdel Rahman. (1987) who stated that garlic can effectively control the growth of Salmonella typhimurium and Campylobacter jejuni, Adler and Beuchat (2002) who observed the inactivation of Listeria monocytogenes occurred more slowly than Escherichia coli with garlic butter, Leuschner and Ielsch. (2002) who concluded that Escherichia coli and Salmonella organisms were inhibited by garlic in a broth model system, Yin and Cheng (2003) who stated that the garlic derived organosulfur compounds can effectively inhibited the growth of Salmonella typhimurium in ground beef, similarly Mousumi Banerjee and Prabir Sarkar (2004) reported that aqueous extract of garlic was a potent bacteriostat against Staphylococcus aureus, Escherichia coli and Salmonella typhimurium and Noori Al-Waili et al. (2007) who reported that Escherichia coli and Staphylococcus aureus were sensitive to garlic juice.

Among the bacterial pathogens tested against the essential oil of clove, the results indicated that Staphylococcus aureus was found to be highly sensitive to its action followed by Salmonella typhimurium, Escherichia coli, Listeria monocytogenes, Methicillin resistant Staphylococcus aureus,
Streptococcus pyogenes, Campylobacter jejuni and Bacillus cereus. The antibacterial activity of essential oil of clove may be attributed to eugenol, the antimicrobial compound of clove. The microbial inhibition of eugenol might be related to either membrane disruption or according to Wendakoon and Sakaguchi (1995), by inactivation of enzymes and genetic material.

The results of this study were in agreement with Matan et al. (2006), who reported complete inhibition of Staphylococcus aureus by application of essential oil of clove, Smith-Palmer et al. (2004), who reported the growth inhibition of Staphylococcus aureus at sub inhibitory concentrations of clove oil, Moreira et al. (2005), who observed the significant bactericidal action of clove against Escherichia coli, Blaszyk and Holley. (1998), who concluded that eugenol inhibited the growth of Escherichia coli $\mathrm{O} 157: \mathrm{H} 7$ and Listeria monocytogenes. Similarly, Vrindamenon and Garg (2001) observed that clove oil at 0.5 and 0.1 percent inhibited the growth of Listeria monocytogenes, Deibel and Banwart (1984), who found that Campylobacter jejuni was sensitive to the action of essential oil of clove, Hoque et al. (2007) determined the antibacterial activity of clove against Staphylococcus aureus, Escherichia coli and Listeria monocytogenes in ground chicken meat. Similarly Abdel Monein E Sulieman et al. (2007) reported that clove oil has a potential antimicrobial activity against Escherichia coli, Staphylococcus aureus and Salmonella typhimurium.

Among the bacterial pathogens tested against the essential oil of cinnamon, the results revealed that Staphylococcus aureus was found to be highly sensitive to its action followed by Escherichia coli, Campylobacter jejuni, Listeria monocytogenes, Salmonella typhimurium, Methicillin resistant Staphylococcus aureus, Streptococcus pyogenes, and Bacillus cereus. The antibacterial activity of essential 
Table 3: Minimum inhibitory concentration of various concentrations of essential oil of clove on the growth of bacterial pathogens

\begin{tabular}{|c|c|c|c|c|c|c|c|}
\hline \multirow[t]{2}{*}{ Bacterial pathogens } & \multicolumn{6}{|c|}{ Various concentrations of essential oil of garlic } & \multirow[b]{2}{*}{$1: 1300$} \\
\hline & $1: 150$ & $1: 250$ & $1: 500$ & $1: 600$ & $1: 700$ & $1: 1000$ & \\
\hline Escherichia coli & ++ & ++ & ++ & ++ & ++ & ++ & ---- \\
\hline Salmonella typhimurium & +++ & +++ & ++ & ++ & + & + & ---- \\
\hline Bacillus cereus & +++ & ++ & ++ & + & --- & ---- & ---- \\
\hline Campylobacter jejuni & +++ & +++ & ++ & ++ & ++ & ++ & + \\
\hline Methicillin resistant $\mathrm{S}$. aureus & ++ & ++ & + & + & ---- & ---- & ---- \\
\hline
\end{tabular}

$+: 08-09 \mathrm{~mm},++: 10-13 \mathrm{~mm},+++: 14-16 \mathrm{~mm}$

oil of cinnamon may be attributed to cinnamaldehyde, the antimicrobial compound of cinnamon. Cinnamaldehyde exhibits its antibacterial activity due to its lipophilicity of terpenoids and phenyl propanoids, which can penetrate the membrane and reach the inner part of the cell and impair bacterial enzyme system (Helander et al. 1998 ).

The results of this study were in consistent with the findings of Bowels et al. (1995) who reported that cinnamon oil inhibited the growth of Staphylococcus aureus, Helander et al. (1998) who observed the inhibition of Escherichia coli O157:H7 and Salmonella typhimurium by the essential oil of cinnamon, Friedman et al. (2002) who found that essential oil of cinnamon was active against Campylobacter jejuni and Escherichia coli, Kwon et al. (2003) who reported that Bacillus cereus was most sensitive to cinnamic aldehyde and Hoque et al. (2007) who reported that essential oil of cinnamon at 5 percent showed highest antibacterial activity against Staphylococcus aureus.

Minimum inhibitory concentration of essential oil of garlic: The minimum inhibitory concentration of essential oil of garlic for various bacterial pathogens are given in Table 2. Among the bacterial pathogens tested, Campylobacter jejuni was found to be most sensitive with a minimum inhibitory concentration of 1:1300, followed by Escherichia coli, Salmonella typhimurium and Staphylococcus aureus with a minimum inhibitory concentration of 1:1000. Listeria monocytogenes is comparatively less sensitive to essential oil of garlic with a minimum inhibitory concentration of 1:150. Among the two strains of Staphylococcus, Staphylococcus aureus was more sensitive (1:1000) than the Methicillin resistant Staphylococcus aureus (1:700). Depending upon the minimum inhibitory concentrations two major clusters of human bacterial pathogens could be observed.
One cluster consists of Campylobacter jejuni, Escherichia coli, Salmonella typhimurium and Staphylococcus aureus, which were more sensitive to the action of essential oil of garlic. The second cluster comprising of Bacillus cereus, Listeria monocytogenes, Streptococcus pyogenes and Methicillin resistant Staphylococcus aureus which were comparatively less sensitive to the action of essential oil of garlic. The microbial inhibitory action of essential oil of garlic may be due to its antimicrobial compound, allicin and the effect will be brought about by its ability to inactivate proteins (Barone and Tansey, 1977) and also by inhibition of RNA synthesis (Feldberg et al. 1988).

Many scientists have tested the efficacy of garlic preparations in inhibiting different bacterial pathogens and reported varying results depending upon the microorganisms tested in their study. The findings of this study were in agreement with ElKhatib and Abdel Rahman. (1987) who concluded that garlic can effectively inhibit Salmonella typhimurium, Kumar and Berwal (1998) who reported Escherichia coli as the most sensitive and Listeria monocytogenes as least sensitive to the inhibitory activity of garlic, Arora and Kaur (1999) reported that Staphylococcus aureus was sensitive to garlic extract, Adler and Beuchat (2002) who have reported rapid decline in salmonella and Escherichia coli $\mathrm{O} 157: \mathrm{H} 7$ counts and a slow inactivation of Listeria monocytogenes in garlic butter. In another study Yin and Cheng. (2003) found that Salmonella typhimurium was much sensitive to the antimicrobial action of garlic derived organosulfur compounds, similarly Mousumi Banarjee and Prabir Sarkar (2004) reported that aqueous extract of garlic was bacteriostat against Staphylococcus aureus, Escherichia coli and Salmonella typhimurium. In a recent study Noori Al-Waili et al (2007) reported that Escherichia coli and Staphylococcus aureus were more sensitive to garlic juice. 
Study on the Antimicrobial activity and Minimum Inhibitory Concentration of Essential Oils of Spices

Table-4: Minimum inhibitory concentration of various concentrations of essential oil of cinnamon on the growth of bacterial pathogens

\begin{tabular}{|c|c|c|c|c|c|c|c|}
\hline \multirow[t]{2}{*}{ Bacterial pathogens } & \multicolumn{6}{|c|}{ Various concentrations of essential oil of garlic } & \multirow[b]{2}{*}{$1: 1300$} \\
\hline & $1: 150$ & $1: 250$ & $1: 500$ & $1: 600$ & $1: 700$ & $1: 1000$ & \\
\hline Escherichia coli & ++ & ++ & ++ & + & + & + & + \\
\hline Salmonella typhimurium & ++ & ++ & ++ & + & + & + & ---- \\
\hline Bacillus cereus & +++ & +++ & ++ & ++ & ++ & ---- & ---- \\
\hline Campylobacter jejuni & ++ & ++ & ++ & ++ & ++ & + & + \\
\hline Methicillin resistant $\mathrm{S}$. aureus & ++ & ++ & + & + & + & + & ---- \\
\hline
\end{tabular}

+: $08-09 \mathrm{~mm},++: 10-13 \mathrm{~mm},+++: 14-16 \mathrm{~mm}$

Minimum inhibitory concentration of essential oil of clove: The minimum inhibitory concentrations of essential oil of clove for various bacterial pathogens are given in Table 3. Among the bacterial pathogens tested, Campylobacter jejuni was found to be most sensitive with a minimum inhibitory concentration of 1:1300, followed by Escherichia coli, Salmonella typhimurium and Staphylococcus aureus (1:1000). Listeria monocytogenes was comparatively less sensitive (1:250). Among the two strains of Staphylococcus, Staphylococcus aureus was more sensitive (1:1000) than the Methicillin resistant Staphylococcus aureus (1:600). Depending upon the results obtained two major clusters of human bacterial pathogens could be observed. One cluster consists of Campylobacter jejuni, Escherichia coli, Salmonella typhimurium and Staphylococcus aureus, which were more sensitive. The second cluster comprising of Bacillus cereus, Listeria monocytogenes, Streptoco-ccus pyogenes and Methicillin resistant Staphyloco-ccus aureus which were comparatively less sensitive to the action of essential oil of clove. The antibacterial activity of clove may be attributed to its antimicrobial compound, eugenol, which may be responsible for cell wall destruction and a high degree of cell lysis (Thoroski et al. 1989).

The efficacy of essential oil of clove was determined by many workers by inhibiting different human bacterial pathogens and reported varying results depending upon the microorganisms tested in their trials. The results of this study were in agreement with Diebel and Banuwart (1984) who reported the bactericidal effect of clove against Campylobacter jejuni. Further the inhibitory activity of clove was also studied by Blaszyk and Holley (1998) and Moreira et al. (2005) and concluded that essential oil of clove at the lowest minimum inhibitory concentration exerted bactericidal action against Escherichia coli. In a recent study Matan et al. (2006) and Abdel Monein E
Sulieman et al. (2007) reported that essential oil of clove inhibited the growth of Staphylococcus aureus. Minimum inhibitory concentration of essential oil of cinnamon : The minimum inhibitory concentrations of essential oil of cinnamon for various bacterial pathogens are given in Table 4. Among the bacterial pathogens tested Campylobacter jejuni and Escherichia coli were found to be most sensitive (1:1300), followed by Salmonella typhimurium, Staphylococcus aureus and Methicillin resistant Staphylococcus aureus (1:1000). Listeria monocytogenes is comparatively less sensitive (1:600). Depending upon the observations made three major clusters of human bacterial pathogens could be observed. One cluster consists of Campylobacter jejuni, Escherichia coli, which were more sensitive followed by Salmonella typhimurium Staphylococcus aureus, and Methicillin resistant Staphylococcus aureus which were sensitive only. The third cluster consisting of Bacillus cereus, Listeria monocytogenes and Streptococcus pyogenes which were less sensitive to the action of essential oil of cinnamon. The antibacterial activity of cinnamon may be due to its antimicrobial compound, cinnamaldehyde, which is considered to bind to proteins and prevents the action of amino acid decarboxylase ( Wendakoon and Sakaguchi, 1995 ).

The efficacy of essential oil of cinnamon in inhibiting different human bacterial pathogens was determined by many workers and reported varying results depending upon the microorganisms tested in their trials. The results of this study were in close agreement with Helander et al. (1998) who found that essential oil of cinnamon inhibits the growth of Escherichia coli 0157:H7 and Salmonella typhimurium, Friedman et al. (2002) reported the strong inhibitory effect of cinnamon on Campylobacter jejuni and Escherichia coli. Matan et 
al. (2006) found that essential oil of cinnamon at $2000 \mu 1$ inhibited the growth of Staphylococcus aureus, similarly Hoque et al. (2007) reported that cinnamon oil at 5 percent had highest antimicrobial activity against Staphylococcus aureus than on Listeria monocytogenes. Further Methicillin sensitive Staphylococcus aureus was found to be less sensitive to essential oil of cinnamon than Methicillin resistant Staphylococcus aureus. It seems that the variability in the resistance of these Gram positive bacteria to the inhibitory action of essential oil of cinnamon may be due to difference between strains of the same species. This was proved by Sivropoulou et al. (1996) with two strains of Staphylococcus aureus in the presence of carvacol and thymol.

\section{Acknowledgement}

Authors are thankful to the Associate Dean, College of Veterinary Science, Tirupati for providing necessary facilities for conducting the present work

\section{References}

1. Abdel Monein E Sulieman, Iman M O E L Bashra and El Amin A. and El Khalifa (2007). Nutritive value of clove (Sazygium aromaticum) and detection of antimicrobial effect of its bud oil. Res. J. Microbiology 2(3): 266-2781.

2. Adler B. B. and Beuchat L. R. (2002). Death of Salmonella, Escherichia coli $\mathrm{O} 157: \mathrm{H} 7$ and Listeria monocytogenes in garlic butter as affected by storage temperature. J. Food Protection 65(12): 1976-1980.

3. Ankri S. and Mirelman D. (1999). Antimicrobial properties of allicin from garlic. Microbes and Infection 1:125-129.

4. Arora D. and Kaur J. (1999). Antimicrobial activity of spices. Int. J. Antimicrobial agents 2:257-262.

5. Banerji Mousumi and Sarkar Prabir K. (2003) Inhibitory effect of garlic on bacterial pathogens from spices. World J.Microbiology and biotechnology 19(6): 565-569.

6. Barone F. E. and Tansey M. R. (1977). Isolation purification, identification, synthesis and kinetics of activity of the anticanadial component of Allium sativam and a hypothesis for its mode of action. Mycologia 69:793-825.

7. Blaszyk M. and Holley R. A. (1998). Interaction of monolaurin eugenol and sodium citrate on growth of common meat spoilage and pathogenic organisms. Int. J. Food Microbiology 39: 175-183.

8. Bowels B. L., Sackitey S. K., and Williams A. C. (1995). Inhibitory effects of flavour compounds on Staphylococcus aureus WRRCB 124. J. Food Safety. 15:337-347.

9. Diebel K. E. and Banwart G. J. (1984). Effect of spices on Campylobacter jejuni at three temperatures. J. Food Safety 6 : 241-251.

10. El-Khatib T. and Abdel-Rahman (1987). Effect of garlic and Lactobacillus plantarum on growth of Salmonella typhimurium in Egyptian fresh sausage and beef burger. $J$. Food Protection 50: 310-311.

11. Feldberg R. S., Chang S. C., Kotic A. N. (1988). In vitro mechanism of inhibition of bacterial cell growth by allicin. Antimicrob. Agents. Chemother 32:1763-68.

12. Friedman M, Henika P. R. and Mandrell R. E. (2002). Bactericidal activities of plant essential oils and some of their isolated constituents against C. jejuni, E. coli, L. monocytogenes and S. enterica. J. Food Protection 65: 1545-1560.

13. Helander I. M., Alakomi H. L., Latva-kala K., Mattila Sandholm T., Pol L., Smid E J., Gorris L. G. M., and Von Wright A. (1998). Characterization of the action of selected essential oil components on Gram negative bacteria. J. Agrl. Food Chem. 46: 3590-3595.

14. Hoque M. D., Inatsu M. L., Juneja, Vijay and Kawamoto S. (2007) Antimicrobial activity of clove and cinnamon extracts against food borne pathopgens and spoilage bacteria and inactivation of Listeria monocytogenes in ground chicken meat with their essential oils. J. Food Sci.\& Tech..72: 9-21.

15. Kumar M. and Berwal J. S. (1998). Sensitivity of food pathogens to garlic (Allium sativum). J. App. Microbiology 84(2): 213-215.

16. Kwon J. A., Yu C. B., and Park H. D. (2003). Bacteriocidal effect and inhibition of cell separation of cinnamic aldehyde on Bacillus cereus. Letters of Applied Microbiology 37 (1): 61-65.

17. Leuschner R.G. K., and Ielsch V. (2003). Antiomicrobial effects of garlic, clove and red hot chilli on Listeria monocytogenes in broth model systems and soft cheese. Int J. Food Sci. and Nutrition 54: 127-133.

18. Matan H., Rimkaeree A. J., Mawson P., Chompreeda V., Haruthaitnanasan and Parker M. (2006). Antimicrobial activity of cinnamon and clove oils under modified atmosphere condition. Int. J. Food Microbiology 107(2): 180-165.

19. Moreira R., Alejandra G Ponce, Carlos E Del valle and Sarai Roura. (2007) Effects of clove and tea tree oils on Escherichia coli $\mathrm{O} 157: \mathrm{H} 7$ in blanched spinach and minced cooked beef. J. Food Processing and Preservation 31(4): 379-391.

20. Noori S Al-Waili., Khelod Y Saloom., M Akmal., Thia N A1Waili., Ali N Al-Waili., Hamza Al-Waili., Amjed Ali., and Karem A-Sahlani. (2007). Effects of heating, storage and ultraviolet exposure on antimicrobial activity of garlic juice. J.Medicinal Food 10(1): 208-212.

21. Ponce A. G., Fritz R., Delvalle C. E., and Roura S. I. (2003). Antimicrobial activity of essential oils on the native microflora of organic swiss chard. Lebensmittelwissemschaft und technologie 36: 679-684.

22. Sivropoulou A., Papanikolaou E., Nikolaou C., Kokkini A., Lanaras T., and Arsenakis M, (1996). Antimicrobial and cytotoxic activities of origanum essential oils. J. Agrl. Food Chem. 44: 1202-1205.

23. Smith-Palmer A., Stewart A., and Fyte L. (2004). Influence of sub inhibitory concentrations of plant essential oils on the production of enterotoxins A\&B and $\alpha$-toxin by Staphylococcus aureus. J.Medical Microbiology 53: 10231027.

24. Thoroski J., Blank G., and Biliaderis C. (1989). Eugenol induced inhibition of extracellular enzyme production by Bacillus subtilis. J. Food Protection 52:399-403.

25. Vrindamenon K., and Garg S. R. (2001). Inhibitory effect of clove oil on Listeria monocytogenes in meat and cheese. Food Microbiology 18(6): 647-650.

26. Wendakoon C. N., and Sakaguchi M. (1995). Inhibition of amino acid decarboxylase activity of Enterobacter aerogenes by active components in spices. J. Food Protection 58:280-283.

27. Yin M. C., and Cheng W. S. (2003). Antioxidant and antimicrobial effects of four garlic derived organosulfur compounds in ground beef. Meat Science 63: 23-28. 